\title{
Chlormethiazole in the treatment of neonatal status epilepticus
}

\author{
P. Miller \\ M.B., M.R.C.P. (U.K.) \\ I. KOVAR \\ M.B., M.R.C.P. (U.K.), F.R.C.P. (C.) \\ Department of Child Health, Westminster Children's Hospital, Vincent Square, London SW1P 2NS
}

\begin{abstract}
Summary
A pre-term neonate with status epilepticus resistant to conventional treatment but who responded to a chlormethiazole infusion is reported. Nineteen days of continuous infusion was required before treatment could be discontinued and oral phenytoin substituted. Chlormethiazole should be considered in the treatment of resistant convulsions in the newborn.
\end{abstract}

KEY WORDS: status epilepticus, neonate, chlormethiazole.

\section{Introduction}

Intermittent convulsions occur in $1 \%$ of neonates (O'Donohoe, 1979); status epilepticus is a less common problem. Drugs that are routinely used to control status epilepticus include phenobarbitone, phenytoin, diazepam and paraldehyde, together with the correction of any metabolic defect. We report a case of a newborn infant who had convulsions which were extremely resistant to conventional treatment and which only responded to an intravenous infusion of chlormethiazole.

\section{Case report}

A female infant was born at 33 weeks gestation, birth weight $2.3 \mathrm{~kg}$, to a 31 -year-old healthy primigravida. There was no family history of epilepsy. Pregnancy was uneventful until premature labour of spontaneous onset; this was arrested for 3 days with a salbutamol infusion and then delivery allowed. The baby was born vaginally with forceps used to protect the head. Minimal resuscitation was required: Apgar scores were 8 at $1 \mathrm{~min}$ and 10 at $5 \mathrm{~min}$. Over the next few hours, signs of respiratory distress developed. Intermittent positive pressure respiration and increased oxygen concentration were required to maintain ventilation and transfer to Westminster Children's Hospital was arranged. Soon after the arrival of the Westminster transport team, the infant developed generalized violent shaking of all limbs and a rapid increase in oxygen requirement. A symptoma- tic diagnosis of status epilepticus was made. Intravenous phenobarbitone $(10 \mathrm{mg} / \mathrm{kg})$ was given with no improvement in the convulsions; a further bolus of $10 \mathrm{mg} / \mathrm{kg}$ only caused slight reduction. Over the next $45 \mathrm{~min}$, intravenous dextrose (2 $\mathrm{ml} 50 \%)$, pyridoxine $(50 \mathrm{mg})$, calcium gluconate $(0.5 \mathrm{ml} 10 \%)$, diazepam $(25 \mathrm{mg})$, intramuscular paraldehyde $(0.5$ $\mathrm{ml})$ and magnesium sulphate $(0.5 \mathrm{ml})$ were given in sequence. Laboratory tests prior to this medication showed $\mathrm{Na}^{+} 140 \mathrm{mmol} /$ litre, $\mathrm{K}^{+} 3.7 \mathrm{mmol} / \mathrm{litre}$, urea $12.7 \mathrm{mmol} /$ litre, $\mathrm{Ca}^{++} 2.1 \mathrm{mmol} /$ litre, $\mathrm{Mg}^{++} 0.8$ $\mathrm{mmol} /$ litre, glucose $5.2 \mathrm{mmol} / \mathrm{litre}$. A lumbar puncture revealed no abnormalities.

The abnormal movements subsided sufficiently to allow transfer to the Westminster Children's Hospital, but on arrival she was markedly irritable and jittery and the convulsions recurred. Partial control was possible with intravenous phenytoin $(10 \mathrm{mg} / \mathrm{kg})$, further intermittent doses of paraldehyde and eventually a diazepam infusion $(0 \cdot 3 \mathrm{mg} / \mathrm{kg} / \mathrm{hr})$. At $18 \mathrm{hr}$ of age, the convulsions persisted and were almost continuous. A chlormethiazole infusion (10 $\mathrm{mg} / \mathrm{kg} / \mathrm{hr}$ ) was started despite there being little information on its use in the neonate. The convulsions stopped promptly but during the next 10 days each time an attempt was made to reduce the chlormethiazole dosage, the convulsions returned. An electroencephalogram (EEG) done at this time showed widespread abnormal bilateral paroxysmal activity; when the EEG was recorded during separate bolus infusions of diazepam, phenytoin and chlormethiazole, the best control of epileptic activity was achieved by the chlormethiazole. It became possible to stop the drug only after 19 days; oral phenytoin was introduced at 16 days.

An ultrasound brain scan at 5 days of age revealed a grade 3 intraventricular haemorrhage; mild hydrocephalus subsequently developed as evidenced by an increasing head circumference and serial ultrasound brain scanning. This initially arrested after a single ventricular tap.

At the age of 10 weeks, her development was normal and there was a social smiling response. An 
EEG revealed only occasional multifocal areas of paroxysmal activity which were particularly evident when she was drowsy.

Progressive hydrocephalus became apparent at 3 months and was managed by insertion of a SpitzHolter valve. At 6 months of age, development was within normal limits, there had been no further convulsions and the phenytoin was discontinued.

\section{Discussion}

Chlormethiazole* has been shown to be an effective anticonvulsant in the control of adult status epilepticus (Harvey, Higgenbottom and Loh, 1976) and in severe toxaemia of pregnancy (Duffus, Tunstall and MacGillivray, 1968). There are few reports of its use in children; Lingam et al. (1980) described a series of children with intractable epilepsy who showed good response. Several problems with the drug have been reported including thrombophlebitis, respiratory depression, drug absorption onto giving sets and dependency with withdrawal. Thrombophlebitis was the only problem that was encountered in this case; peripheral intravenous lines remained patent for at most $12 \mathrm{hr}$ and eventually a central long-line was inserted to maintain the constant infusion.

The cause of the convulsions in this patient remains speculative. No metabolic abnormality was found, the delivery was not traumatic, the Apgar scores did not suggest birth asphyxia; respiratory

*Chlormethiazole-Heminevrin/Astra Pharmaceuticals Ltd. distress syndrome together with a presumed hypo period and intraventricular haemorrhage are the most likely possibilities.

The reasons for the resistance to convention $\overrightarrow{\mathrm{Al}^{1}}$ therapy are equally uncertain. A vicious cycle 8 f convulsions leading to increased cerebral oxyggn consumption and cerebral hypoxia leading to furth $\frac{5}{\sqrt{3}} \mathrm{r}$ convulsions may have been responsible. Chlormethazole proved to be extremely effective in thits situation where other drugs were not. We feel that chlormethiazole should be considered in neonate्gl status epilepticus not responding to conventional drug treatment. We are not aware of any previouss reports of the use of this drug in the neonatal periø.

\section{Acknowledgments}

We thank Professor D. Barltrop for his advice concerning this report.

\section{References}

Duffus, G.M., Tunstall, M.E. \& MacGillivray, I. (1968) Intravenous chlormethiazole in pre-eclamptic toxaemia in labotr. Lancet, i, 335.

HARVEY, P.K., HigenbotToM, T.W. \& LOH, L. (1976) Chlormeth? zole in treatment of status epilepticus. British Medical Journa 603.

Lingam, S., BerTwistle, H., Elliston, H.M. \& Wilson, J. (19 Problems with intravenous chlormethiazole (Heminevrin) @in status epilepticus. British Medical Journal, 1, 155.

O'DONOHOE, N.V. (1979) Epilepsies of Childhood. 1st edn., $\frac{0}{9} \overrightarrow{96}$ Butterworth Press, London.

(Accepted 11 January 1983) 